13-ARTIGOORIGINAL

\title{
Concentrações séricas de imunoglobulinas em sangue do funículo umbilical e em sangue materno no momento do parto ${ }^{1}$
}

\author{
Hideaki Cláudio Hironaka ${ }^{2}$ \\ Lucy Duailibi Casanova ${ }^{3}$
}

\begin{abstract}
Hironaka, HC, Casanova LB. Concentrações séricas de imunoglobulinas em sangue do funículo umbilical e em sangue materno no momento do parto. Acta Cir Bras [serial online] 2003 MarAbr;18(2). Disponível em URL: http://www.scielo.br/acb.

RESUMO - Objetivo: Identificar as concentrações das imunoglobulinas no sangue do funículo umbilical comparando-as às do sangue materno no momento do parto. Métodos: Foram analisadas amostras colhidas de $323 \mathrm{RN}$ e de 321 mães pelo método de turbidimetria. Os resultados foram submetidos à análise estatística, estabelecendo-se coeficiente de correlação $r$ e nível de significância p 0,05 . As retas de regressão obedeceram ao limite de $95 \%$. Resultados: Houve aumento progressivo de $\operatorname{IgG}$ sérica do $\mathrm{RN}$, diretamente proporcional à idade gestacional $(\mathrm{r}=0,31 ; \mathrm{p}=0,0001)$; quanto ao peso de nascimento, esta relação não foi tão evidente $(\mathrm{r}=0,14 ; \mathrm{p}=0,008)$, possivelmente por estarem incluídos na amostra RNPT e RN com restrição ao crescimento intrauterino. $\mathrm{O}$ aumento da $\operatorname{IgG}$ do $\mathrm{RN}$ foi maior que o da mãe $(\mathrm{r}=0,20 ; \mathrm{p}=0,0001)$. Houve queda de concentração da $\operatorname{IgM}$ com o aumento da idade materna e aumento da $\operatorname{IgM~e} \operatorname{IgA}$ maternas comparadas à $\mathrm{IgG}$ do RN. Observou-se queda da concentração de $\mathrm{IgG}$ do funículo umbilical quando relacionada ao tempo maior de ruptura da bolsa $(r=-0,13 ; p=0,018)$. Conclusões: A concentração de $\operatorname{Ig} G$ no funículo umbilical aumentou proporcionalmente à idade gestacional e diminuiu com tempo maior de ruptura de membranas. Concentrações de $\operatorname{IgM}$ e $\operatorname{IgA}$ no sangue materno aumentaram significativamente quantdo comparadas à $\mathrm{IgG}$ do funículo umbilical e a IgM diminuiu significativamente com o aumento da idade materna.
\end{abstract}

DESCRITORES - Imunoglobulina. Sangue do cordão umbilical. Parto. Recém-nascido.

\section{Introdução}

A sepse bacteriana continua sendo um problema sério nos berçários, com incidência variando de 1 a 10 casos / 1000 nascidos vivos e com incidência ainda mais alto nos $\mathrm{RN}$ baixo peso.Em estudo do Ministério da Saúde a taxa de infecção hospitalar nas UTIs neonatonais foi $46,9 \%$, mais elevada que nas unidades para queimados ou em UTIs pediátricas ${ }^{1}$

Dados da UNIFESP, Escola Paulista de Medicina, referentes a 1997, mostram incidência acumulada de infecção hospitalar em UTI neonatal $=25,6 / 100$ saídas (174 RN) ou 9,3 infecções/100 pacientes (considerando-se os $186 \mathrm{RN}$ admitidos no período),segundo Farhat, $2000^{2}$. No Hospital do Servidor Público Estadual "Francisco Morato de Oliveira", a taxa de infecção hospitalar de 19,17/1000 $\mathrm{RN}$ dia para $<1.500 \mathrm{~g}$ e de 11,03 para $\mathrm{RN}$ entre 1.500 e $2.500 \mathrm{~g}$. Apesar dos avanços nas medidas preventivas e terapêuticas, a mortalidade continua alta, variando de $15 \%$ a $50 \%{ }^{4}$. Saindo de um ambiente relativamente estéril, os RN entram em contacto, logo após o nascimento, com

1. Trabalho apresentado para obtenção do Título de Mestre em Medicina - IAMSPE-SP.

2. Mestrando - Área de Concentração em Clínica Médica - IAMSPE-SP.

3. Doutora em Medicina pela EPM-UNIFESP / Orientadora da Tese. 
bactérias potencialmente infectantes e que podem atingilos através da conjuntiva, do aparelho respiratório e do trato digestório ou ainda através da pele. Além destas vias, se a mãe está infectada, o $\mathrm{RN}$ pode ser atingido por germes através da placenta.

As barreiras com que o $\mathrm{RN}$ conta para se defender das infecções estão inicialmente comprometidas. A pele, principalmente no RN pré-termo, é imatura e tem permeabilidade aumentada, estando, além disso, sujeita a punções ou procedimento cirúrgicos que facilitam a entrada de bactérias por essa via. A falta de IgA torna vulneráveis os epitélios dos tratos respiratório e digestório.

Tanto a imunidade celular como a humoral estão comprometidas no RN. O transporte de $\operatorname{IgG}$ através da placenta, que se inicia na $15^{\text {a }}$ semana de gestação, só é máximo após a $32^{a}$ semana de idade gestacional ${ }^{5}$. $\mathrm{O} \mathrm{RN}$ de termo tem concentrações de $\mathrm{IgG}$ iguais ou até maiores que as de suas mães. $\operatorname{Ig} \mathrm{A}$ e $\operatorname{IgM}$ não são transportadas através da placenta e suas concentrações no feto e no $\mathrm{RN}$ estão muito diminuídas em relação às da criança maior e às do adulto. As proteínas do complemento são sintetizadas pelo feto, mas a ativação hemolítica do complemento do RN de termo e normal é igual à metade daquela encontrada na mãe ${ }^{6}$.

Os linfócitos estão em número normal no $\mathrm{RN}$ e têm função adequada em situações normais. A mobilidade, assim como a adesividade, é menor quando se trata de linfócito T. Há poucos dados quanto à fagocitose, que parece estar diminuída ${ }^{7}$. Os linfócitos B apresentam na superfície IgG ou IgA comparável no adulto, mas o defeito está na função. O nível de RNA mensageiro para a cadeia de imunoglobulina $d$ nas células mononucleares é inferior aos das células de adulto ${ }^{8}$.

Neutrófilos de RN sadios têm fagocitose e capacidade de matar levemente diminuída, função que é mais comprometida na presença de estresse $\mathrm{e}^{4,6}$. Toda esta dificuldade na luta contra as infecções deixa claro a necessidade de diagnóstico e de tratamento precoces, assim como, para melhorar o prognóstico da sepse neonatal, de usar-se recursos tais como imunoglobulina endovenosa, transfusão de plasma, de neutrófilos, exsangüíneotranfusão e ainda outros recursos que possam minimizar o dano tecidual provocado pela infecção.

\section{Objetivo}

Comparar as concentrações de imunoglobulinas no sangue do funículo umbilical de $\mathrm{RN}$ com as do sangue de suas mães no momento do parto.

\section{Métodos}

No período compreendido entre 09 de setembro de 1993 e 30 de março de 1994 foram coletadas amostras de sangue de parturientes no momento do parto e de sangue do funículo umbilical de seus RN, coletas estas feitas no Centro Obstétrico do Hospital do Servidor Público Estadual "Francisco Morato de Oliveira". Apesar de terem sido colhidas no período referido amostras de todas as parturientes e de seus recém-nascidos, foram incluídos na pesquisa apenas os pares (mãe/RN) que obedecessem aos critérios de inclusão e de exclusão abaixo discriminados:

\section{Critérios de inclusão}

Foram incluídos os pares mãe/RN que tivessem todos os dados exigidos no protocolo de trabalho, preenchidos e confiáveis, assim como os que tivessem os soros mãe/funículo umbilical armazenados, independentemente de idade gestacional, tipo de parto, sexo, condições de nascimento, peso do $\mathrm{RN}$ ou ainda de qualquer patologia por este apresentada.

\section{Critérios de exclusão}

Foram excluídos os binômios em que se verificassem:

- Identificação duvidosa ou controversa do registro da mãe e do $\mathrm{RN}$ ou do nome da mãe.

- Preenchimento incorreto de idade da mãe, data de nascimento, idade gestacional, tempo de ruptura de membranas, número de gestações, número de abortos anteriores, tipo de parto.

- Preenchimento incorreto ou ausência de dados referentes ao $\mathrm{RN}$ : peso de nascimento, sexo, cor, boletim Apgar de $1^{\circ}$ e de $5^{\circ}$ minutos.

- Coleta apenas de sangue da mãe ou só do RN; identificação duvidosa dos tubos, soros hemolisados.

Adotados estes critérios, de 1077 fichas preenchidas, puderam apenas ser analisados os soros de 323 $\mathrm{RN}$ e de 321 mães, uma vez que havia dois pares de gêmeos.

\section{Delineamento experimental}

$\mathrm{O}$ estudo programado foi do tipo prospectivo. $\mathrm{O}$ protocolo inicial foi submetido à aprovação da Comissão de Ética Médica deste Hospital; na ocasião da realização deste estudo não se adotava ainda o hoje obrigatório consentimento pós-informado. 


\section{Análise laboratorial}

As amostras coletadas foram centrifugadas e os soros foram guardados no freezer a $-20^{\circ} \mathrm{C}$, aos pares (mãe/RN), em tubo Eppendorf ${ }^{\circledR}$.As amostras foram descongeladas à temperatura ambiente, homogeneizadas e a dosagem foi feita de forma a utilizar reagentes e padrões pertencentes a um único lote em rotinas de 100 amostras/dia.

Para se ter uma idéia a respeito da relação entre as concentrações de imunoglobulinas no sangue do funículo umbilical e as de imunoglobulinas do sangue periférico do RN, foram colhidas cinco amostras do sangue do funículo umbilical e, nas primeiras 24 horas de vida, cinco amostras de sangue periférico dos mesmos RN, tendo sido possível verificar correspondência entre os valores obtidos.

As concentrações séricas foram dosadas pelo método de turbidimetria com o aparelho Behringer Turbitime System (Alemanha) e com o reagente Turbiquant $^{\circledR}$ reagents para IgG, IgA e IgM. Por este método, o limiar de reatividade para $\mathrm{IgG}$ é $100 \mathrm{mg} / \mathrm{dl}$, para $\operatorname{IgA}, 40 \mathrm{mg} / \mathrm{dl}$ e para $\operatorname{IgM}, 25 \mathrm{mg} / \mathrm{dl}$.

A leitura é feita com comprimento de onda de $340 \mathrm{~nm}$, com lâmpada de xenônio. A turbidez é dada pela reação do anticorpo presente na amostra contra o anticorpo antiimunoglobulina $(\operatorname{Ig} G, \operatorname{Ig} A, \operatorname{Ig} M)$ com formação de imuno-complexo insolúvel que produz turvação no meio.

O bloqueio de luz por estes imuno-complexos é medido a $180^{\circ} \mathrm{C}$ de feixe incidente. A leitura é inversamente proporcional à concentração das imunoglobulinas.

\section{Planejamento estatístico}

Os dados deste trabalho foram analisados considerando-se um nível de significância de 5\% (r£0,05).

Foram utilizados os seguintes modelos:

1-Média aritmética e desvio padrão, valor mínimo e máximo

2-Teste de Associação: correlação paramétrica de Pearson

3-Equação da reta de regressão linear, coeficiente de correlação e suas significância

4-Cálculo de intervalo de confiança e de regressão linear, para valor médio ao nível de $95 \%$

5-Gráficos de regressão linear

\section{Resultados}

\section{Características maternas}

TABELA 1 - Média aritmética, desvio padrão, valores máximo e mínimo para os diversos parâmetros das 321 mães.

\begin{tabular}{ccccc}
\hline Variáveis & Média & $\begin{array}{c}\text { Desvio } \\
\text { Padrão }\end{array}$ & Mínimo & Máximo \\
\hline Idade mãe (anos) & 27,99 & 6,68 & 15 & 46 \\
$\mathrm{~N}^{\text {o de gestações }}$ & 2,42 & 1,61 & 1 & 13 \\
Abortos & 0,31 & 0,78 & 0 & 8 \\
Tempo de ruptura da bolsa & 3,93 & 10,75 & 0 & 103 \\
\hline
\end{tabular}

Caracteríscas do $R N$

TABELA 2 - Média aritmética, desvio padrão, valores máximo e mínimo das características de 323 RN Quanto à idade gestacional, peso e boletim Apgar.

\begin{tabular}{ccccc}
\hline Variáveis & Média & $\begin{array}{c}\text { Desvio } \\
\text { Padrão }\end{array}$ & Mínimo & Máximo \\
\hline Idade Gestacional (semana) & 39,11 & 1,78 & 32,4 & 42,8 \\
Peso ao nasc.(gramas) & 3180,93 & 527,56 & 1430 & 5040 \\
Boletim Apgar $1^{\circ}$ Min & 7,85 & 1,65 & 1 & 10 \\
$5^{\mathbf{0}}$ Min & & & & \\
\hline
\end{tabular}


TABELA 3 - Distribuição dos RN por tipo de parto e sua porcentagem.

\begin{tabular}{ccc}
\hline Tipo de Parto & $\mathbf{N}^{\mathbf{0}}$ & Porcentagem\% \\
\hline Normal & 135 & 41,8 \\
Fórceps & 26 & 8,1 \\
Cesária & 162 & 50,1 \\
\hline
\end{tabular}

TABELA 4 - Distribuição dos RN por sexo e sua porcentagem.

\begin{tabular}{ccc}
\hline Sexo & $\mathbf{N}^{\mathbf{0}}$ & Porcentagem\% \\
\hline Masculino & 167 & 51,7 \\
Feminino & 156 & 48,3 \\
Indeterminado & 0 & 0,0 \\
\hline
\end{tabular}

TABELA 5 - Distribuição dos RN por cor e sua porcentagem.

\begin{tabular}{c|c|c}
\hline Cor & $\mathbf{N}^{\mathbf{0}}$ & Porcentagem\% \\
\hline Leucodérmico & 241 & 74,6 \\
\hline Malenodérmico & 82 & 25,4 \\
\hline Total & 323 & 100 \\
\hline
\end{tabular}

\section{Concentrações de Imunoglobulinas}

TABELA 6 - Média aritmética, desvio padrão, valores mínimo e máximo de 644 soros, sendo 321 soros de mães e 323 de RN.

\begin{tabular}{ccccc}
\hline Variáveis & Média & $\begin{array}{c}\text { Desvio } \\
\text { Padrão }\end{array}$ & Mínimo & Máximo \\
\hline IgG mat (mg\%) & 1188,53 & 296,89 & 340 & 2620 \\
IgM mat(mg\%) & 176,33 & 91,18 & 17 & 547 \\
IgA mat(mg\%) & 277,07 & 79,48 & 73 & 567 \\
IgG mat(mg\%) & 1390,62 & 291,47 & 491 & 2195 \\
\hline
\end{tabular}

TABELA 7 - Imunoglobulinas: correlação entre os diversos parâmetros (Paramétrica de Pearson).

\begin{tabular}{lll}
\hline IgG RN x Id. Gestacional & $\mathrm{r}=0,31669$ & $\mathrm{p}=0,0001$ \\
\hline IgG RN x Peso & $\mathrm{r}=0,1474$ & $\mathrm{p}=0,008$ \\
\hline IgG Mat. x IgG RN & $\mathrm{r}=0,20648$ & $\mathrm{p}=0,0001$ \\
\hline IgM Mat. X IgG RN & $\mathrm{r}=0,12717$ & $\mathrm{p}=0.022$ \\
\hline IgA Mat. X IgG RN & $\mathrm{r}=0,17537$ & $\mathrm{p}=0,002$ \\
\hline IgM Mat. X Id. Mat. & $\mathrm{r}=-0,1246$ & $\mathrm{p}=0,025$ \\
\hline IgG RN x Tempo de Rup. Bolsa & $\mathrm{r}=-0,1314$ & $\mathrm{p}=0,018$ \\
\hline IgG Mat. x IgA Mat & $\mathrm{r}=0,16304$ & $\mathrm{p}=0,003$ \\
\hline IgG Mat. x IgM Mat. & $\mathrm{r}=0,13729$ & $\mathrm{p}=0,014$ \\
\hline
\end{tabular}


Matriz de correlação entre as diversas imunoglobulinas e os diversos parâmetros com a coeficiência de correlação de Pearson ${ }^{\circledR}$ para nível de significância de $5 \%(p=0,05)$

A matriz de correlação entre as diversas imunoglobulinas com os diversos parâmetros para o total de

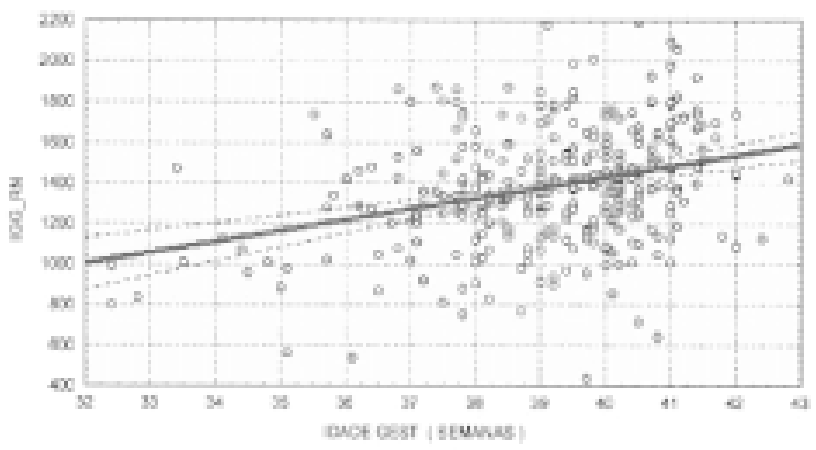

FIGURA 1 - Reta de regressão e equação correspondente de IgG do RN com a idade gestacional

IGG_RN $\left(\mathrm{mg}^{\%}\right)=689,5+\mathrm{I}$ GEST (SEMANAS)

Correlação: $r=0,31669 \quad \mathrm{p}=0,0001$

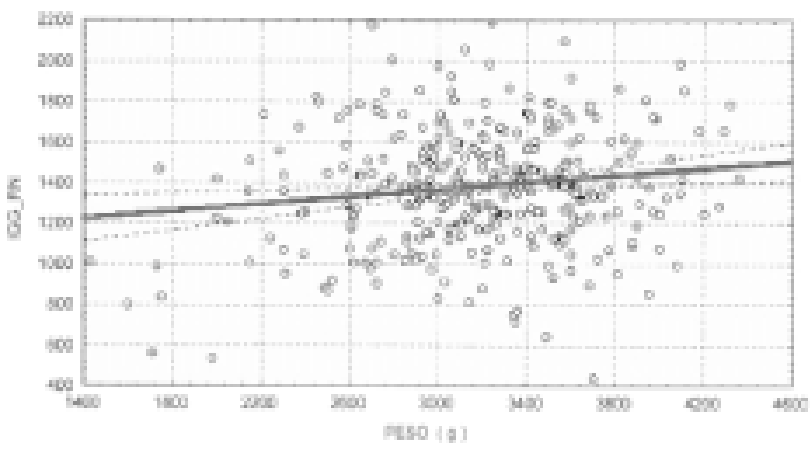

FIGURA 2 - Reta de regressão e equação correspondente da relação $\mathrm{IgG}$ do $\mathrm{RN}$ e peso de nascimento

IGG_RN(mg\%) $=1117,1+0,08255 * \operatorname{PESO}(\mathrm{g})$

Correlação: $\mathrm{r}=0,1474 \quad \mathrm{p}=0,008$

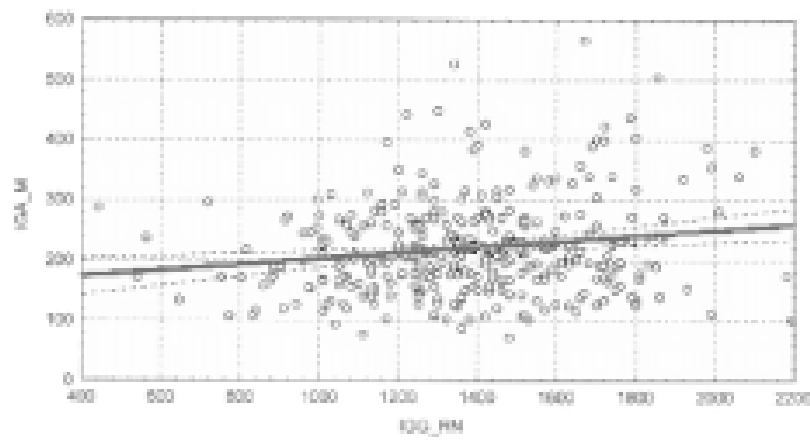

FIGURA 5 - Reta de regressão e equação correspondente da relação IgA materna com IgG do RN

IgA_M $\left(\mathrm{mg}^{2} \mathrm{o}\right)=153,04+0,04852 *$ IGG_RN $(\mathrm{mg} \%)$ Correlação: $r=0,17537 \quad p=0,002$
$323 \mathrm{RN}$ apresentada na Tabela 7 estabelecida para o nível de significância (p) de $5 \%(\mathrm{p}=0,05)$; através dela construíram-se gráficos de regressão linear (-), equação da reta, coeficiente de correlação (r) e sua significância (p). Cálculo do intervalo de confiança da regressão linear de $95 \%$ para o valor médio foi representado no gráfico pela linha (----------).

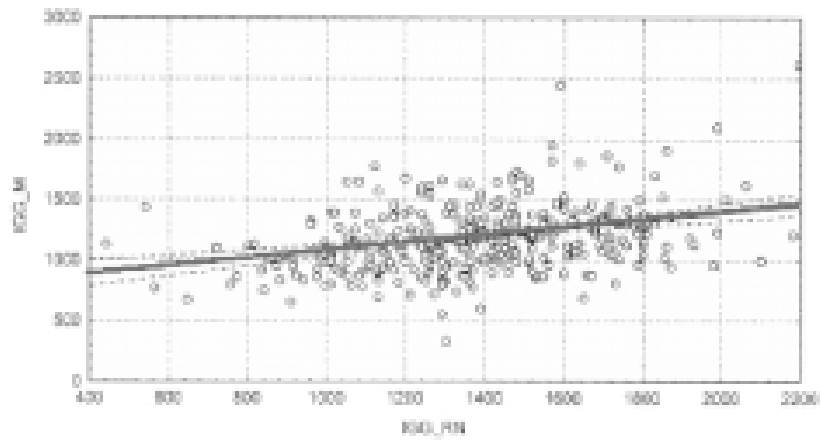

FIGURA 3 - Reta de regressão e equação correspondente da IgG materna com IgG do RN

IGG_M $(\mathrm{mg} \%)=771,92+0,31252 * \mathrm{IGG} \mathrm{RN}(\mathrm{mg} \%)$

Correlação: $r=0,20648 \quad \mathrm{p}=0,0001$

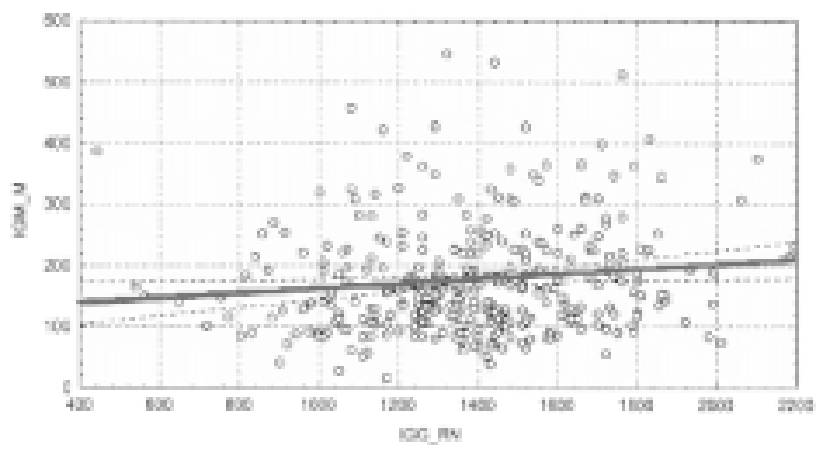

FIGURA 4 - Reta de regressão e equação correspondente da IgM materna com IgG do RN

$\operatorname{IgM} \mathrm{M}(\mathrm{mg} \%)=121,58+0,3978 * \mathrm{IGG} \mathrm{RN}(\mathrm{mg} \%)$

Correlação: $r=0,12717 \quad p=0,022$

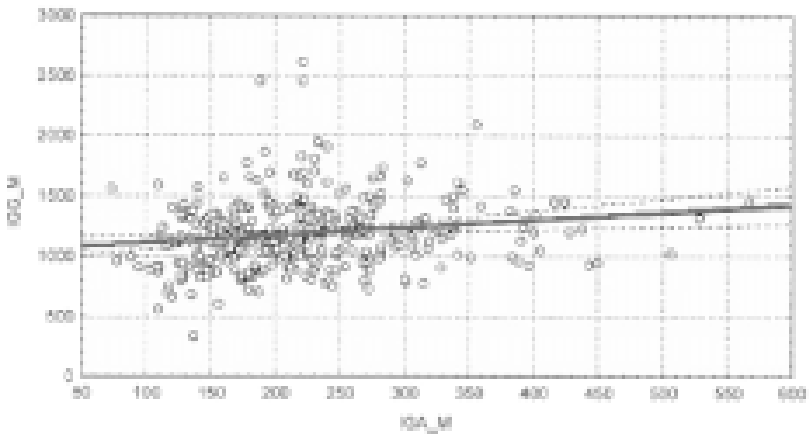

FIGURA 6 - Reta de regressão e equação correspondente da relação IgG materna com IgA Materna

IGG_M $(\mathrm{mg} \%)=1053,3+0,60897 *$ IGA_M $(\mathrm{mg} \%)$ Correlação: $r=0,16304 \quad \mathrm{p}=0,003$ 


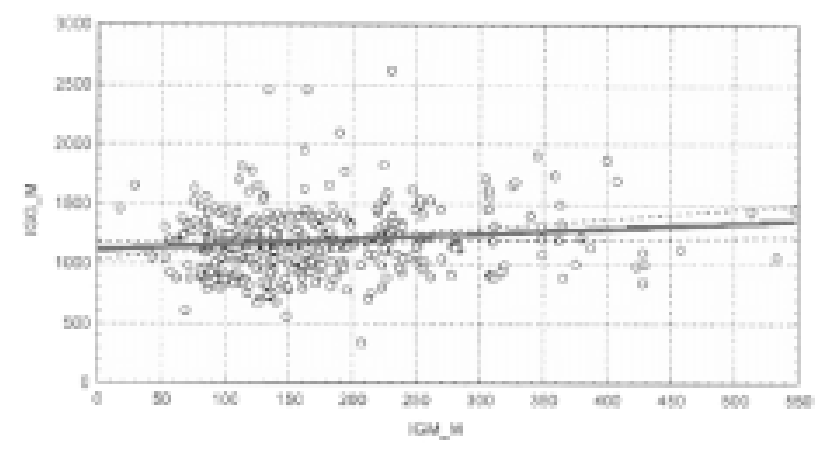

FIGURA 7 - Reta de regressão e equação correspondente da relação IgG materna com IgM materna

IGG_M $(\mathrm{mg} \%)=1109,7+0,44699 * I G M \_M(m g \%)$

Correlação: $r=-0,13729 \quad \mathrm{p}=0,014$

\section{Discussão}

A importância da passagem transplacentária de imunoglobulinas para o feto, dando a este proteção a processos infecciosos no período neonatal, foi o motivo de iniciar este trabalho, um estudo prospectivo visando conhecer as concentrações de imunoglobulinas no sangue da mãe e do funículo umbilical.A susceptibilidade às infecções é maior no $\mathrm{RN}$ pré-termo do que no $\mathrm{RN}$ de termo. Além da menor defesa e da maior manipulação a que estão sujeitos, os RN pré-termo recebem quantidades menores de imunoglobulinas através da placenta, uma vez que a passagem transplacentária ocorre principalmente a partir da $32^{\mathrm{a}}$ semana de vida intra-uterina.

As altas taxas de morbidade e de mortalidade neonatal por infecções despertaram interesse em todos nós, neonatologistas, em conhecer um pouco mais as condições imunológicas do $\mathrm{RN}$;pesquisas a respeito foram sendo desenvolvidas em todo o mundo, inclusive no Brasil ${ }^{9}$.

Comparados os níveis de $\mathrm{IgG}$ em sangue venoso materno e em sangue de artéria e de veia umbilical, foi verificado que, no final da gestação (37-42 semanas de idade gestacional), os níveis de $\operatorname{IgG}$ na artéria e também na veia umbilical excediam os níveis maternos ${ }^{9}$. IgG3 e IgG4 tinham concentrações iguais em artérias e veia umbilical, IgG2 aumentava com a idade gestacional, permanecendo em níveis inferiores aos maternos. $\mathrm{O}$ maior aumento deveu-se a $\operatorname{IgGl}$, aumento este que se deu tanto no sangue arterial como no sangue venoso ${ }^{10}$.

Para análise das variáveis obtidas neste trabalho, usou-se coeficiente de correlação, com significância de $5 \%(\mathrm{p}=$ ou $<0,05)$; escolheram-se os pares analisados, construindo-se retas de regressão.

Observou-se, neste estudo, aumento progressivo da IgG sérica do RN com o avanço da idade gestacional,

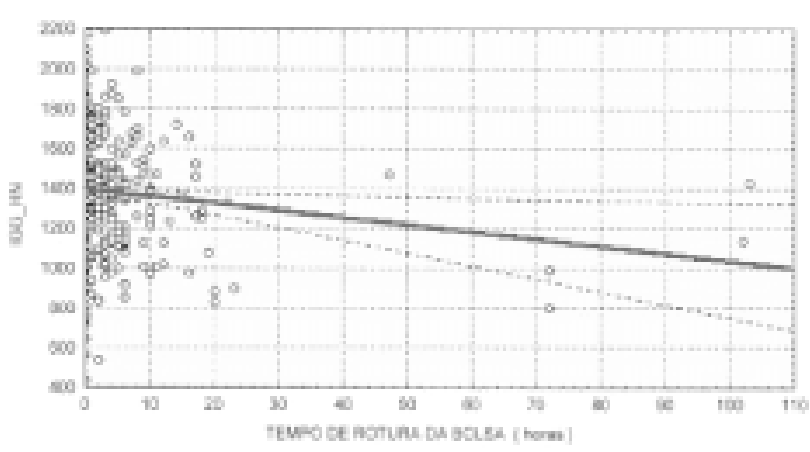

FIGURA 8 - Reta de regressão e equação correspondente da relação $\operatorname{IgG}$ do Rne tempo de ruptura da bolsa âmnica

IGG_RN $(\mathrm{mg} \%)=1394,1-3,562 *$ BOLSA ROTA $($ HORAS $)$

Correlação: $r=0,1314 \quad \mathrm{p}=0,018$

isto é, o aumento foi diretamente proporcional à idade gestacional, o que já havia sido verificado por vários autores $\mathrm{s}^{9,10,11,12,13}$.

Comparando-se as concentrações de $\operatorname{IgG}$ do $\mathrm{RN}$ com a idade gestacional em semanas, o coeficiente de

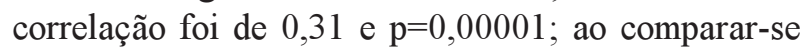
concentrações de $\operatorname{IgG}$ do $\mathrm{RN}$ com o peso ao nascer, encontrou-se coeficiente de 0,14 e p=0,008. As retas de regressão que manifestam de maneira muito clara o aumento da IgG com o progredir da idade gestacional não manifestaram de maneira tão evidente uma correlação com o peso de nascimento, apesar de haver significância estatística. Estes achados devem-se, possivelmente, ao fato de em nossa amostra estarem incluídos tanto RNT (recém-nascido de termo) como RNPT (recém-nascido pré-termo) e RNPIG (recémnascido pequeno para a idade gestacional). $\mathrm{O}$ estudo das concentrações de imunoglobulinas G, M e A em RNPT e em RN com restrição ao crescimento intrauterino, mostrou que as concentrações de $\mathrm{IgG}$ eram baixas em RNPT PIG; os aumentos de IgA e de IgM não foram estatisticamente significantes ${ }^{14}$. Estudada a transferência de $\mathrm{IgG}$ e suas subclasses em RNT e em RNPT, foi verificado o aumento de $\operatorname{IgG} 1$ e IgG3 com a idade gestacional, atingindo concentrações iguais às maternas na $37^{\text {a }}$ semana $^{9}$. As concentrações eram menores em RN prematuros.Há trabalhos em mães/ $\mathrm{RN}$ verificando as concentrações de $\operatorname{IgG}$ específica para vírus de sarampo, herpes simples tipo 1, vírus sincicial respiratório, vírus varicela/zoster, toxóide tetânico, toxóide diftérico e Streptococcus pneumoniae encontrando-se níveis significantemente menores em RNPT e em RNPIG ${ }^{15}$. Por outro lado, entretanto, as concentrações eram significantemente mais baixas de $\mathrm{IgG}$ e de $\mathrm{IgM}$ em crianças com peso inferior a $2.000 \mathrm{~g}$, enquanto que nas diferentes classes de $\operatorname{IgA}$ e na $\operatorname{IgD}$ não foi encontrada diferença significante ${ }^{16}$. 
O estudo de concentrações maternas de $\operatorname{IgG}$ comparando com as dos funículo umbilical mostrou diferença significantemente maior no sangue do $\mathrm{RN}$, fazendo supor que, além de transporte por gradiente, a $\operatorname{IgG}$ seria transportada ativamente ${ }^{17}$. Foi encontrado na circulação fetal um receptor (fosfatase alcalina) para imunoglobulina $\mathrm{G}$, receptor esse relacionado aos níveis de ligações para IgG no sangue fetal, e os autores consideraram que o transporte ativo é o responsável pelos níveis mais altos no sangue fetal que no materno. O transporte seletivo placentário da $\mathrm{IgG}$ e de seus subgrupos, baseados nas estruturas de carboidratos, torna atrativa e consistente a hipótese de que a interação da IgG se faz com células de superfície na fração y (Fcy) receptoras e dependentes de carboidratos. Entretanto, sugere-se que, além do transporte dependente de carboidratos com seleção de $\mathrm{IgG}$ altamente galactosilada, o transporte pode ser feito por mecanismo independente de carboidrato ${ }^{18}$

$\mathrm{O}$ aumento de $\mathrm{IgG}$ materna quando comparada ao da $\operatorname{IgG}$ do $\mathrm{RN}$ e significante, o que poderia ocorrer por estímulo antigênico fetal ou por maior freqüência de infecções maternas durante a gestação. $\mathrm{O}$ mesmo ocorreu com a $\operatorname{IgA}$ materna quando correlacionada às concentrações de $\mathrm{IgG}$ do funículo umbilical.

É pequeno o número de pesquisas ${ }^{10}$ comparando as concentrações de $\operatorname{IgM}$ e de $\operatorname{IgA}$ em mãe de RN, contrastando com o grande número de trabalhos relacionados a $\operatorname{Ig} \mathrm{G}^{15-16}$. Há aumento de $\operatorname{IgM}$ e de $\operatorname{IgG}$ na gestação de termo, as concentrações de $\operatorname{Ig} \mathrm{A}$ e de $\operatorname{IgD}$ praticamente não se modificaram com a idade gestacional. Aumento de IgM e de IgA relacionado com aumento do pêso de nascimento, sem significância estatística $^{14}$. A análise de IgA em sangue materno, em sangue fetal colhido por cordocentese ou ainda por colheita em funículo umbilical, mostrou aumento na circulação fetal entre 17 e 41 semanas de idade gestacional; a IgA fetal mostrou aumento linear com concentração, ao termo, às vezes maior que a da circulação materna ${ }^{11}$.

Correlacionando-se IgM materna com a idade materna, à medida que a idade materna avançou, houve queda nas concentrações de IgM, dado esse que, isolado pode nada significar, mas que deverá levar às investigações relacionadas à imunidade humoral da gestante mais idosa. Não encontramos referência a este fato, o que atribuímos a que, em muitos estudos, foram excluídas as mães com idade extremas ${ }^{9}$.

Feita a correlação entre a concentração de IgG do funículo umbilical e a ruptura prematura da membrana, verificou-se haver queda desta concentração com o maior tempo de ruptura de bolsa (coeficiente-0,1314 $\mathrm{p}=0,018)$. Este dado poderia mostrar perda de $\operatorname{IgG}$ no liquido âmnico, maior consumo ou manutenção de gestação para evitar parto prematuro. Não foi encontrada relação entre concentrações de $\mathrm{IgG}$ ao nascimento e tempo de ruptura das membranas, independente de haver ou não infecção.

Os resultados desta pesquisa mostram discreta queda de concentrações de imunoglobulinas na circulação materna com o progredir da gestação. Concentrações de $\operatorname{IgG}$ e de IgA apresentaram um nível de $60 \%$ a $70 \%$ menores que as do início da gestação entre 17 41 semanas $\mathrm{IG}^{11}$.

\section{Conclusões}

1. As concentrações de $\operatorname{Ig} G$ aumentaram no sangue do funículo umbilical dos $\mathrm{RN}$ com avanço da idade gestacional atingindo, no termo, concentrações superiores aos de suas mães.

2. Houve diminuição nas concentrações de $\operatorname{Ig} G$ do sangue do funículo umbilical dos RN relacionada ao tempo maior de ruptura de membranas.

3. As concentrações de $\operatorname{IgM}$ e $\operatorname{Ig} \mathrm{A}$, determinadas no sangue venoso materno, tiveram aumento significante quando comparadas à concentração de $\operatorname{IgG}$ do funículo umbilical.

4. Houve queda significante das concentrações de $\operatorname{IgM}$ quando relacionadas ao aumento da idade materna.

\section{Referências}

1. Prade SS, Oliveira ST, Rodrigues R, Nunes FA, Netto EM, Félix JQ e col. Estudo brasileiro da magnitude de infecção hospitalar em hospitais terciários. Revista do Controle de Infecção Hospitalar1995; 2:11-24.

2. Farhat CK. Infecção hospitalar. J Pediatria 2000; 76:259-65.

3. Alves Filho MB, Bianchini PJ. Série Histórica da Morbidade. Período 1998-1999. Hospital do Servidor Público Estadual "Francisco Morato de Oliveira".

4. Klein OJ, Marcy M. Bacterial sepsis and meningits in Remington \& Klein, (eds) Infectious Diseasesof the fetus and the newborn, 4a ed. Philadelphia, WB Saunders, 1995 pp835-90.

5. Yeung CY, Hobbs Jr. Serum gamma-globulin levels in normal, premature, post-mature, and small for date newborn babies. Lancet $1968 ; 1: 1167-70$.

6. Edwards M. Complement in neonatal infectious. An Overview. Pediatr Infect Dis J 1986; 5:168-70.

7. Wilson CB. Lung antimicrobial defense in the newborn. Semin Respir Med Dis 1984; 128:149-155.

8. Wedgwood JF, Weinberg BI, Hatam L, Palmer R. Umbilical cord blood lacks circulating lymphocytes expressing surface IgG or IgA. Clin Immunol Immunopathol, 1997; 84:276-82.

9. Costa-Carvalho BR, Vieira HMS, Dimantas RBR, Arslanian C, Naspitz CK, Sole D, Carneiro-Sampaio MM. IgG subclass transfer across placenta in term and preterm newborn. Brazilian J Med Biol Res 1996;29:201-204. 
10. Malek A, Sager R, Schneider H. Maternal-fetal transport of immunoglobulin $\mathrm{G}$ and its subclasses during the third trimester of human pregnancy. Am J Reprod Immunol 1994;32:8-14

11. Malek A, Sager R, Kuhn P, Niconides KH, Schneider H. Evolution of materno-fetal transport of immunoglobulins during human pregnancy. Am J Reprod Immunol; 199636:248-55.

12. Palfi M, Selbing A. Placental transport of maternal immunoglobulin G. Am J Reprod Immunol 1998; jan 39(1):24-6.

13. Hashira S, Oktsu-Negishi S, Yoshino K. Placental transfer of IgG Subclasses in a Japanese population. Pediatr Int 2000; 43:337-42.

14. Sharma S, Laf H, Saigal RK. Immunoglobulins IgG, IgM and IgA levels in preterm and small for date newborn. Indian Pediatr $1991 ; 28: 741-4$.

15. Wesumperuma HL, Pereira AJ, Phariah PO, Hart CA. The influence of prematury and low birthweight on transplacental antibody transfer in Sri Lanka. Ann Trop Med Parasitol 1999; $93: 169-77$.
16. Cederqvist LL, Ewool LC and Litwim SD. The effect of fetal age, birth weight and sex on cord blood immunoglobulin values. Am J Obst Gynecol 1978; 131:520-25.

17. Kohler PF and Farr RS. Elevation of cord over maternal immunoglobulin - evidence for an active placental IgG transport. Nature 1966; 210:1070-1.

18. Williams PJ, Arkwright PD, Rudd P, Scragg Ig, Edge CJ, Wormald MR, Rademocher TW. Short communications: Selective placental transport of maternal IgG to the fetus. Placenta 1995;16:749-56.

19. Machado AP, Gonçalves G, Barros H, Nascimento MS. Motherchild transmission of immunoglobulins G. Acta Med Port 1995; $8: 81-5$.

20. Cederqvist LL, Zervoudakis IA, Ewool LC, Litwin SD. The relationship between prematurely ruptured membranes and fetal immunoglobulin production. Am J Obst Gynecol 1978; 134:784-8.

Hironaka HC, Casanova LB. Immunoglobulins concentration in umbilical cord blood and in maternal blood at delivery. Acta Cir Bras [serial online] 2003 Mar-Apr;18(2). Available from URL: http://www.scielo.br

ABSTRACT - Purpose: To compare the immunoglobulins concentration in umbilical cord blood and in venous maternal blood at delivery. Methods: imunoglobulin's concentration was determined by Behringer turbitime System from serum samples of 323 umbilical cords and 321 peripheral maternal veins. The results were statistically analysed, correlation coeficient $\mathrm{r}$ was calculated; statistical significance established at $p=$ or $<0,05$, with regression curves limit of $95 \%$. Results: $\operatorname{IgG}$ concentracion progressively increased with gestational age $(\mathrm{r}-0,31 ; \mathrm{p}=0,0001)$ and with increasing birth weight $(0,14 ; \mathrm{p}=0,08)$. The relation with birth weight, although significant was not so expressive as with gestational age probably depending of inclusion of preterm and intrauterine groowth restraint infants in the data. IgG concentracion was higher in cord blood than in mother's serum $(\mathrm{r}=0,02 ; \mathrm{p}=0,0001)$. IgM concentracion lowers as mother's age increases. Mother's IgM and $\operatorname{IgA}$ were higher if comparad to $\mathrm{IgG}$ of cord blood; $\mathrm{IgG}$ of cord blood lowes as time of rupture of membranes increeases $(\mathrm{r}=-0,13 ; \mathrm{p}=0,018)$. Conclusions: $\mathrm{IgG}$ concentracion increases with increasing gestational age and lowers as the time of rupture of membranes increases. IgM and IgA of maternal blood are higher when compared to $\mathrm{IgG}$ of umbilical cord. IgM lowers when maternal age increases.

KEY WORDS - Immunoglobulins. Umbilical cord blood. Delivery. Newborn.

Conflito de interesse: nenhum Fonte de financiamento: nenhuma

Correspondência:

Hideaki Claudio Hironaka

Rua Napoleão de Barros, 1075/91

04024-003 São Paulo - SP

Tel.: (11) 5549-9567 / 9271-0899

Data do recebimento: 20/10/2002

Data da revisão: 04/11/2002

Data da aprovação: 09/01/2003 